\title{
A SECOND BARRED OWL NEST RECORD FOR SASKATCHEWAN
}

\author{
by R. E. Gehlert, 12155 - 96 Street, Edmonton
}

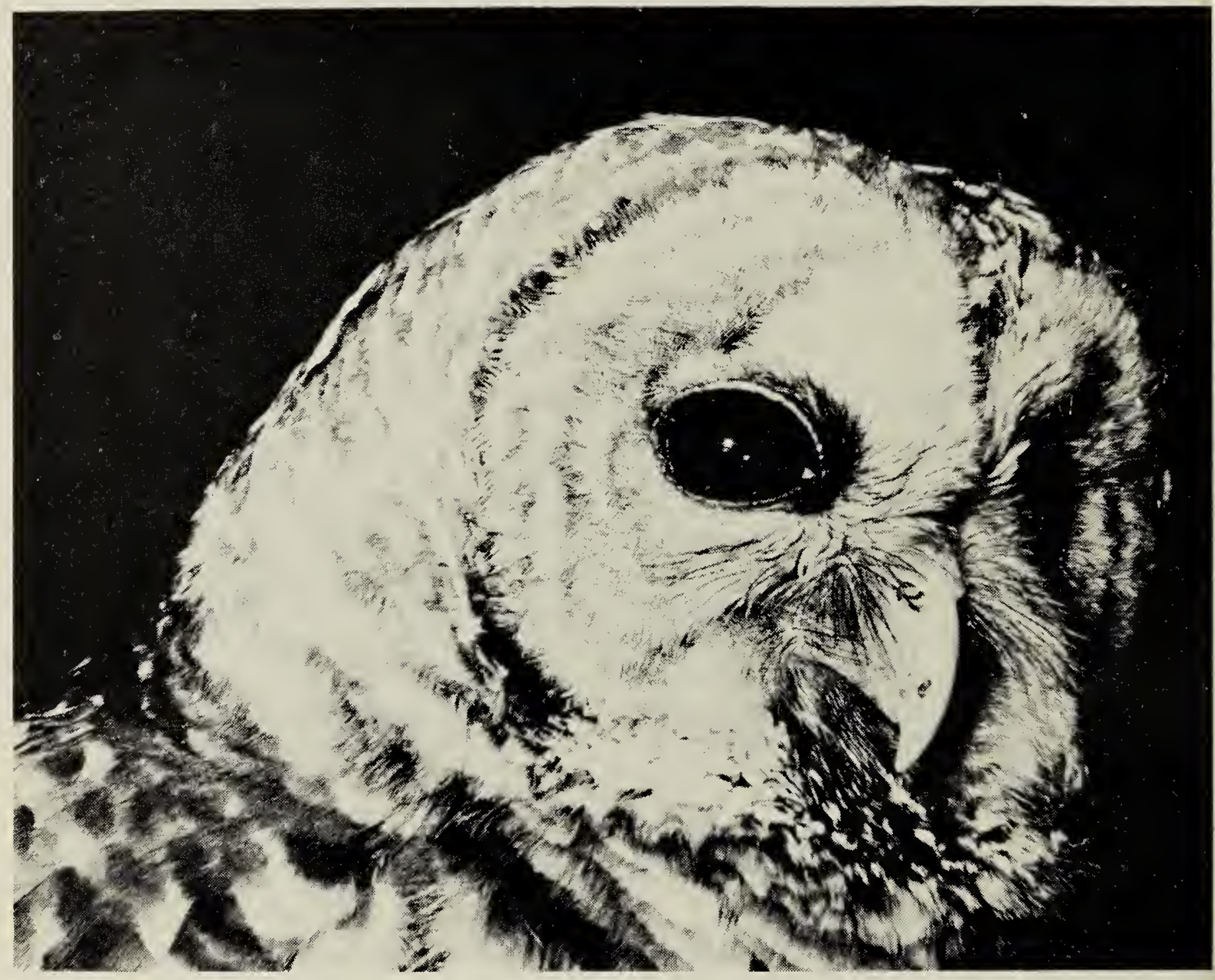

Barred Owl male, Emma Lake, 1970.

F'hoto by R. E. Gehlert

On May 6, 1970, while checking a raven's nest at Emma Lake, I heard the distinctive call of a Barred Owl (Strix varia). I promptly located the calling bird in a spruce tree when a second owl was heard. A brief search of the area revealed a nest of a Barred Owl on top of a 20-foot decayed stump.

Both adults were captured and banded on May 9. A later attempt to reach the nest with a ladder in order to band the owlets was abandoned for fear of toppling the rotten tree. Consequently, the contents of the nest were never established, although on June 14 at least one downy young could be seen peering out of the cavity.

I also heard a Barred Owl at Mistohay Lake in Meadow Lake Provincial Park on June 21, 1970.

The first Barred Owl specimen for Saskatchewan was obtained in 1959 (Houston, Blue Jay, 17:94) and the first nest was discovered in 1961 (Houston, Blue Jay, 19:114). The species had previously been reported in Saskatchewan as far west as Dore Lake (Folker, Blue Jay, 21:14) and north to Beaverlodge Lake (Birds of the Lake Athabasca region, Saskatchewan, Nero, 1963). 